\title{
Research Paper \\ Assessment Geo-Sites in the Villages of Chahardange Using Fasilous and Nicholas Method (Case Study: Villages of Chahardangeh, City of Sari)
}

\author{
*Sadegh Salehei ${ }^{1}$, Zeynab Aflaki ${ }^{2}$, Hossein Mousazadeh ${ }^{3}$, Zeynab Zangiabadi ${ }^{3}$ \\ 1. Assistant Professor, Department of Social Sciences, Faculty of Humanities \& Social Sciences, University of Mazandaran, Babolsar, Iran \\ 2. MSc. Student, Department of Climatology and Geomorphology, Faculty of Geography and Environmental Sciences, Hakim Sabzevari University, Sabzevar, Iran. \\ 3. MSc. Student, Department of Geography and Urban Planning, Faculty of Humanities, University of Golestan, Gorgan, Iran.
}

Citraton: Salehei, S., Aflaki, Z., Mousazadeh, H., \& Zangiabadi, Z. (2016). An assessment of Geo-Sites Using Fasilous and Nicholas Method (Case Study: Villages of Chahardangeh, City of Sari). Journal of Rural Research, 7(2), 300-315.

Received: 7 Feb 2016

Accepted: 19 May 2016

Key words:

Geotourism

Geomorphosites,

Nicholas method,

Fasilous method,

Chahardange section

\section{A B STRACT}

Currently, one of the factors for attracting tourism is the natural resources of the country that resulted in natural tourism in the region. Natural tourism emphasizes on geomorphosites with geomorphic locations, and they assay on the historic, ecological and cultural potentials to program Mize stable tourism. The Chahardange section is a geographical zone with a high potential for attracting rural tourism. The project used geology and topological maps and exact reviews based on the Nicholas and Fasilous methods. The Fasilous final assessment method was used to identify the proper site that represents the ideal conditions in terms of geomorphological processes. The Nicholas method revealed that the sources of Surat-Badab achieved the highest score of 33 points. The results also revealed that the top-rated site was identified to have physical and unique beauty. Thus, the Chahardange zone needs to identify and to property stable tourism development at crucial programs. Moreover, scientific and topological grades and conservative and useable potentials must be imported as per geomorphosites.

\section{Extended Abstract}

\section{Introduction}

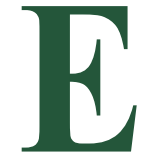

cotourism plays a significant role in the global economic development and provides a bigger opportunity for development. Geotourism as a new phenomenon is defined as informed and responsible tourism of nature with the purpose of viewing and understanding the formation and evolution of phenomena and processes and learning their method of formation and evolution (Amrikazemi, 2009). Sometimes instead of sites- in terms of geomorphology-geomorphological value goods, geomorphology and geomorphic to work
(Kumansju et al., 2009). The purpose of such concepts is to help identify the particular importance of understanding the structure of the geomorphologic landforms that has regional and scientific values and ecological, cultural, aesthetic, and economic benefits and in order to understand and exploit the tourism exploited by humans (Yamani, 2012). This study aimed to assess ecological, economic, and social capacity of the studied area and finding basic mechanisms to protect geoheritage and developing sustainable tourism.

\section{Methodology}

In this research, the required information and data were gathered by reviewing library studies and the relevant

\section{* Corresponding Author:}

Sadegh Salehei, PhD

Address: Department of Social Sciences, Faculty of Humanities \& Social Sciences, University of Mazandaran, Babolsar, Iran.

Tel: +98 (11) 25342658

E-mail: s.salehi.umz@gmail.com 
literature. The potential and capabilities of Suort-Badab sources for ecotourism were examined using two methods: Fasilous and Nicholas. In the Fasilous method, the criteria and definition parameters were composed of six main groups such as scientific values, ecological values and conservation, cultural, aesthetic and economic values of tourism's potential. Each of these values consisted of several sub-standard and standard scoring system of 1 to 10 for each specified group.

In the Nicholas method, the specific criteria for determining each of the aspects of tourism in geomorphological sites had been identified, including scientific, educational, geological and ecological diversity, aesthetic potential threats and potential protection needs. In this way, each of the above values was scored by a group of experts. Based on the values expressed by certain rating, the overall value of the area was determined.

\section{Results}

The results of the study showed the final assessment by applying Fasilous method. According to the tables that have been created by applying Fasilous final assessment method, the proper site was identified that represented the ideal conditions in terms of geomorphological processes. The results also indicated the richness of the geology and history of the region. In terms of tourism, the index of protection, which received either the highest score or the lowest score, refers to the site's natural and human destruction and damages. Furthermore, the results of the study revealed the lack of official attention to the site and indiscriminate harvesting of travertine rocks and mining in the region. The natural vision in terms of tourism has favorable conditions.

Furthermore, based on the final assessment by Nicholas method, the total values were determined as 72 points in accordance with the table. Based on the final assessment of the spring Suort-Badab with applying Nicholas method, the sources of Suort-Badab rural area of science has achieved the highest score with 33 points. The results also revealed that physical beauty and rarity of their top rated site was identified perhaps as a national and international source.

\section{Discussion}

One of the best mechanisms for developing sustainable tourism is to consider tourism sites and geosites. In this research, Suort-Badab was analyzed as a geosite and the assessment showed that this site has scientific as well as educational values to attract tourists. In some area, we need to promote some indices to develop tourism. The results of this research are consistent with the results of some other studies like Charmamine and Fung (2015).

\section{Conclusion}

One of the most favorite way for achieving sustainable tourism development, with focus on geo-tourism is considering sites that makes interaction between tourism and the nature. It results of the previous studies show that the number of tourists and incoming currency from tourism has boomed in recent decades. It is assumed that natural tourism and tourist services, in turn, increase educational values, cultural, economic impact, but it may meanwhile damage the current properties which leads to threaten the available sites. In this study, the current situation of geo Suort-Badab sources with an emphasis on existing values was assessed and evaluated by Fasilous and Nicholas. The result of the evaluation showed that SuortBadab sources as geo-park and world's second largest natural effect, has received high percentage with regard to values such as aesthetic and scientific values. Due to continuous using travertine stones which increases the potential harm, water boiling has damaged the geo-park and this type of destruction has damaged its beauty. How many correct decisions and taking charge? It is recommend to prepare those programs which protect Sites from destruction and prevent the decline of the tourism Sites. 


\title{
ارزيابى رئوسايتهاى تحردشَّى با روش فاسيلوس و نيكولاس (مطالعه موردى: روستاهاى بخش جههاردانتَه شهرستان سارى عردى
}

\author{
"صادق صالحى'، زينب افلاكى"، حسين موسىزاده"، زينب زنكى آبادى" \\ 1- إنشيار، كروه علوم اجتماعى، دانشكده علوم انسانى واجتماعى، دانشكاه مازندران، بابلسر، ايران.

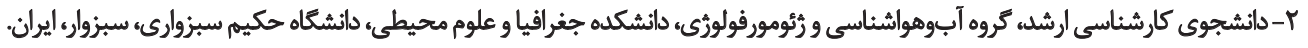

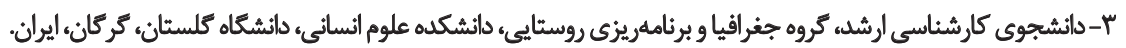

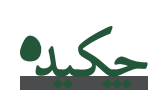

تاريخ دريافت: 14 بهيمن

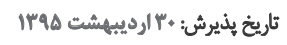

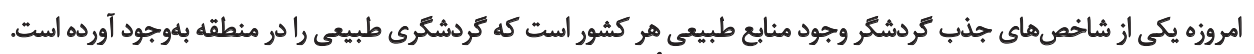

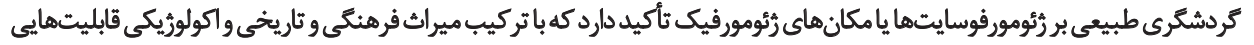

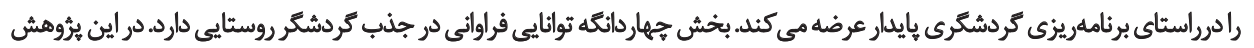

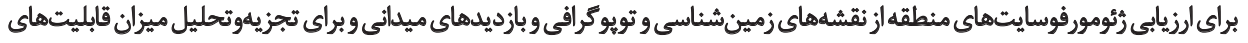

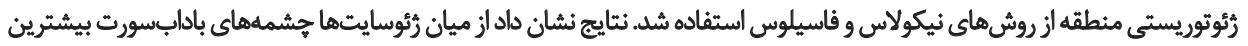

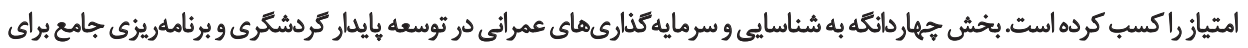

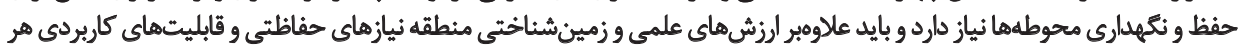

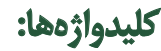

روتوتوريسه، رئومورفوسايت،

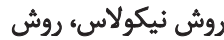

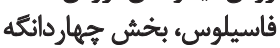

ويثراى در درك ساختار رئومورفولوريك يك منطقه دارد و از ارزشهاي

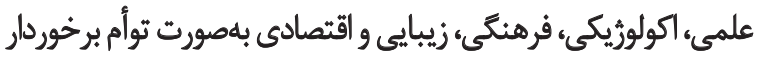

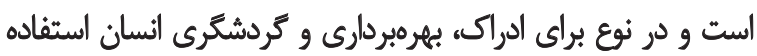
مىشود (Yamani, Negahban, Rahimi Abad, \& Alizadeh, 2012).

حفاظت از ميراث زمينشئاختى براى تفرج، مقاصد آموزشى و علمى

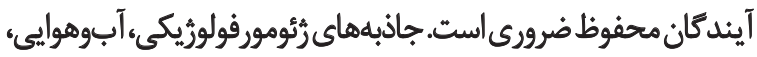

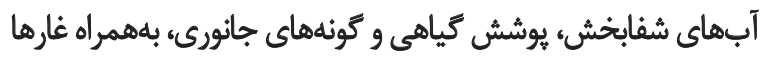

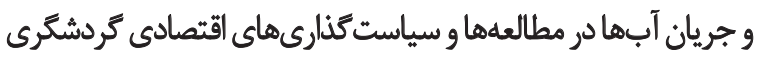

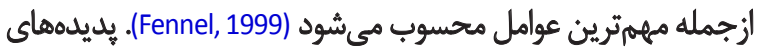

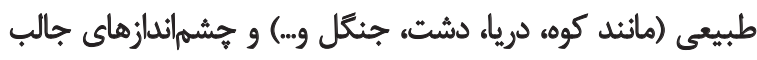

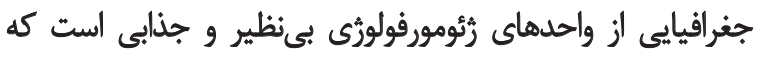

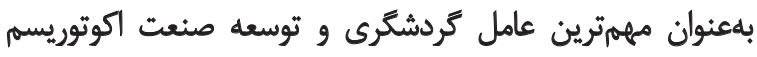

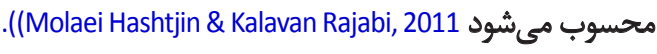

ميراث زمينشناسى به مجموعالى كفته مي شود كه براى حفاظت

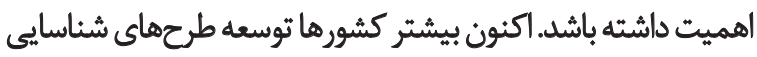

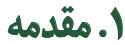

كردشكرى نقش بسيار مهمى را در توسعه اقتصادى جهان

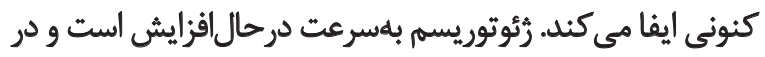

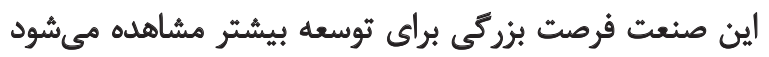

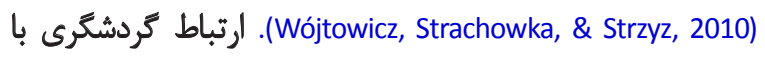

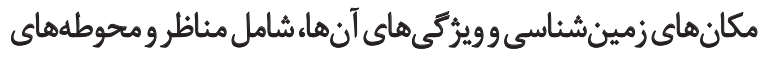

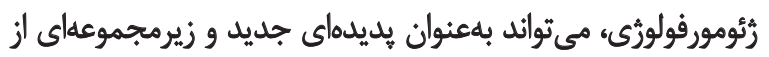
زمينشناسى و گردشكَّى مطرح شود (Joyce, 2010).

رئوتوريسه، كردشكَى آكاهانه و مسئولانه از طبيعت با هدف

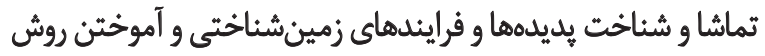

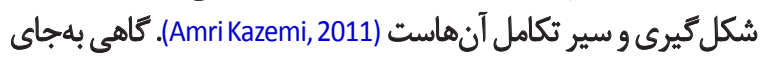

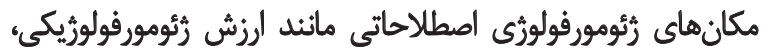

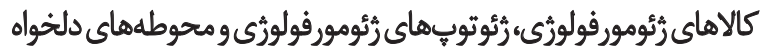

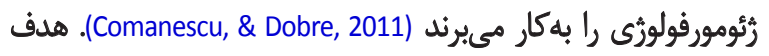

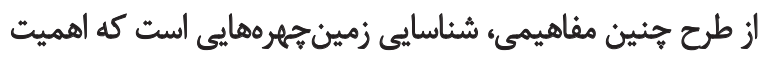




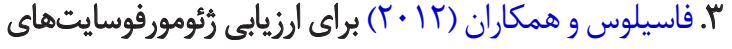

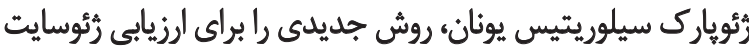

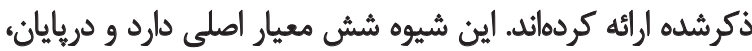

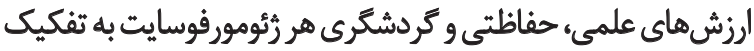
مشخص و معين شده است.

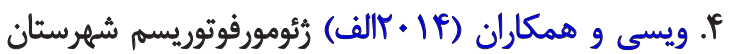

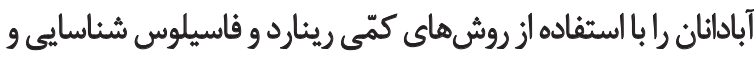

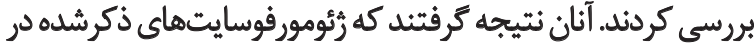

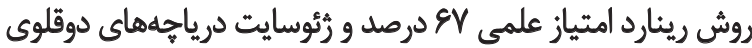

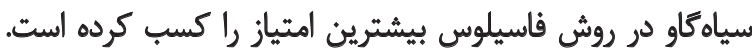

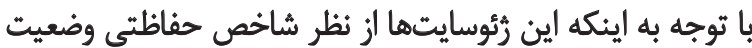
مطلوبى ندارد، به توجه مسئولان نياز دارد.

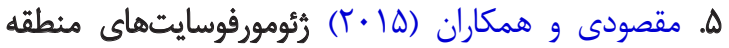

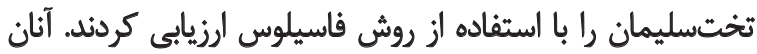

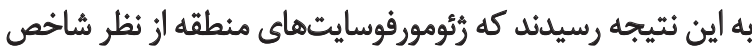

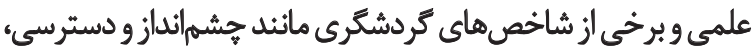

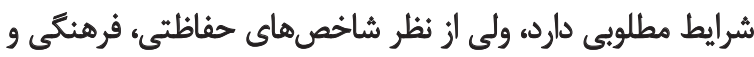
هنرى نيازمند تقويت است.

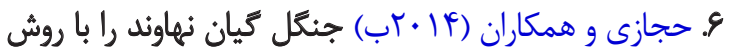

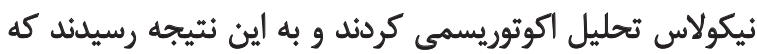

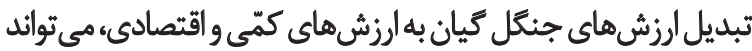

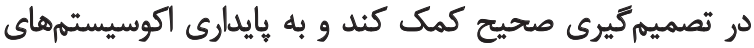

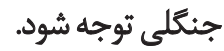

V. ويسى و جيتساز (If إب) رئومورفوسايتهاى منطقه

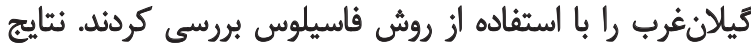

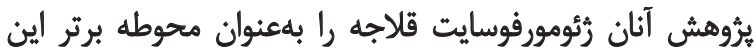

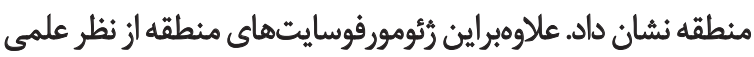

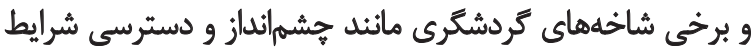

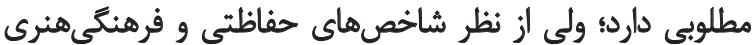

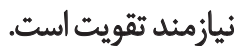

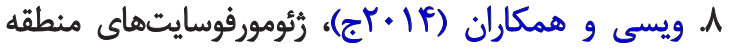

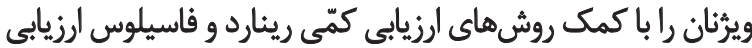

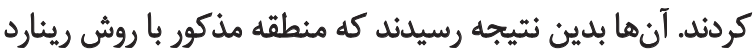

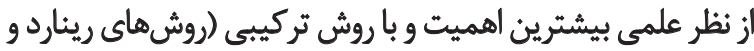

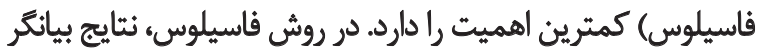

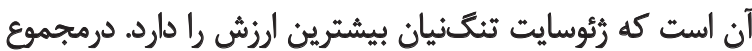

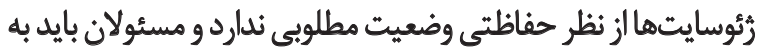
اين محوطهها توجه بيشترى داشته باشند.

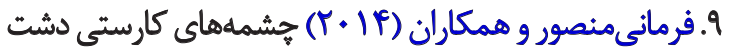

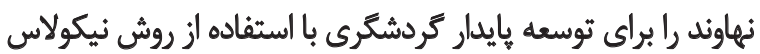

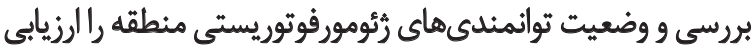

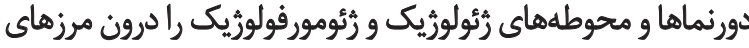

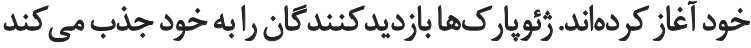

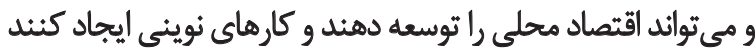
بun \& Milly, 2002)

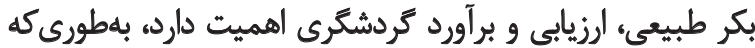

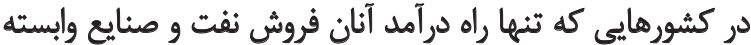

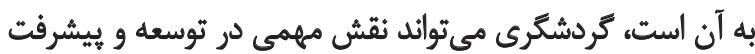
اقتصادى، اجتماعى و فرهنكى منطقه ايفا كند.

علاوهبر اهميت كردشكَى مسئله مهرم ديكر حفاظت ازئ

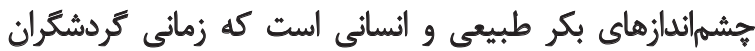

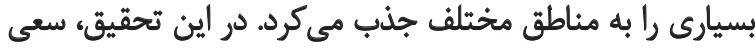

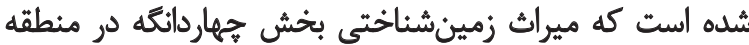

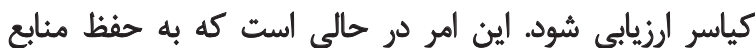

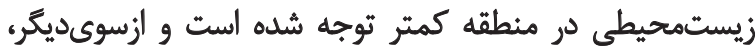

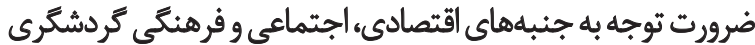

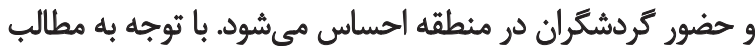

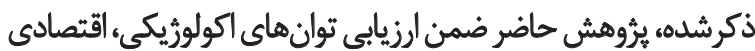

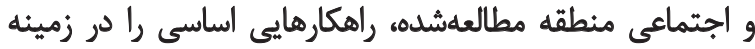

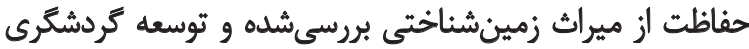

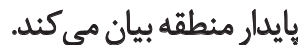

\section{T. آمرورى بر الديباث موضوع}

در سال هاى اخير با توجه به نقش و اهميت محوطهها و ميراث

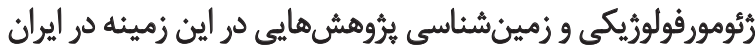

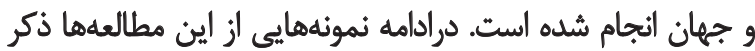

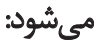
ا. ميركتولى و همكاران (90سا) با الكوى نوينى ميراث

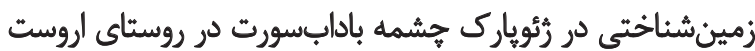

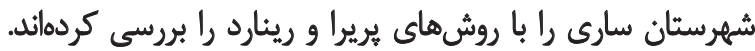

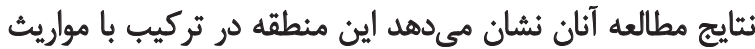

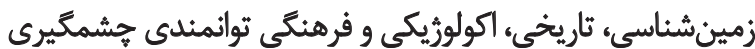

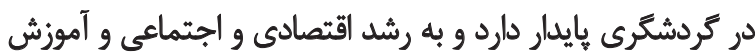

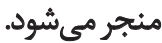

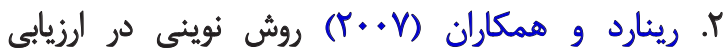

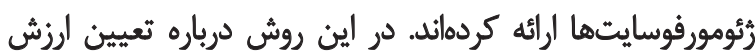

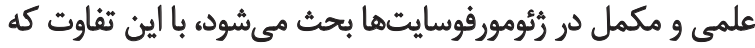

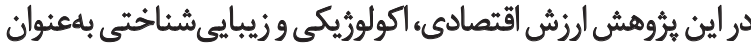

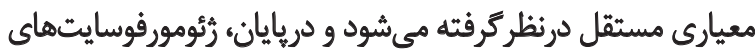

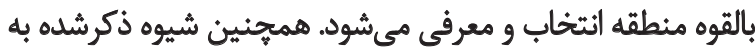

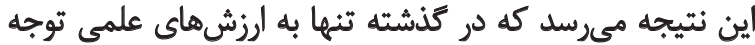

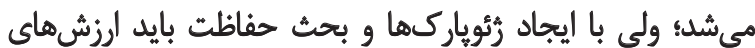
مكمل در كنار ارزش هائ علمى بررسى شود. 

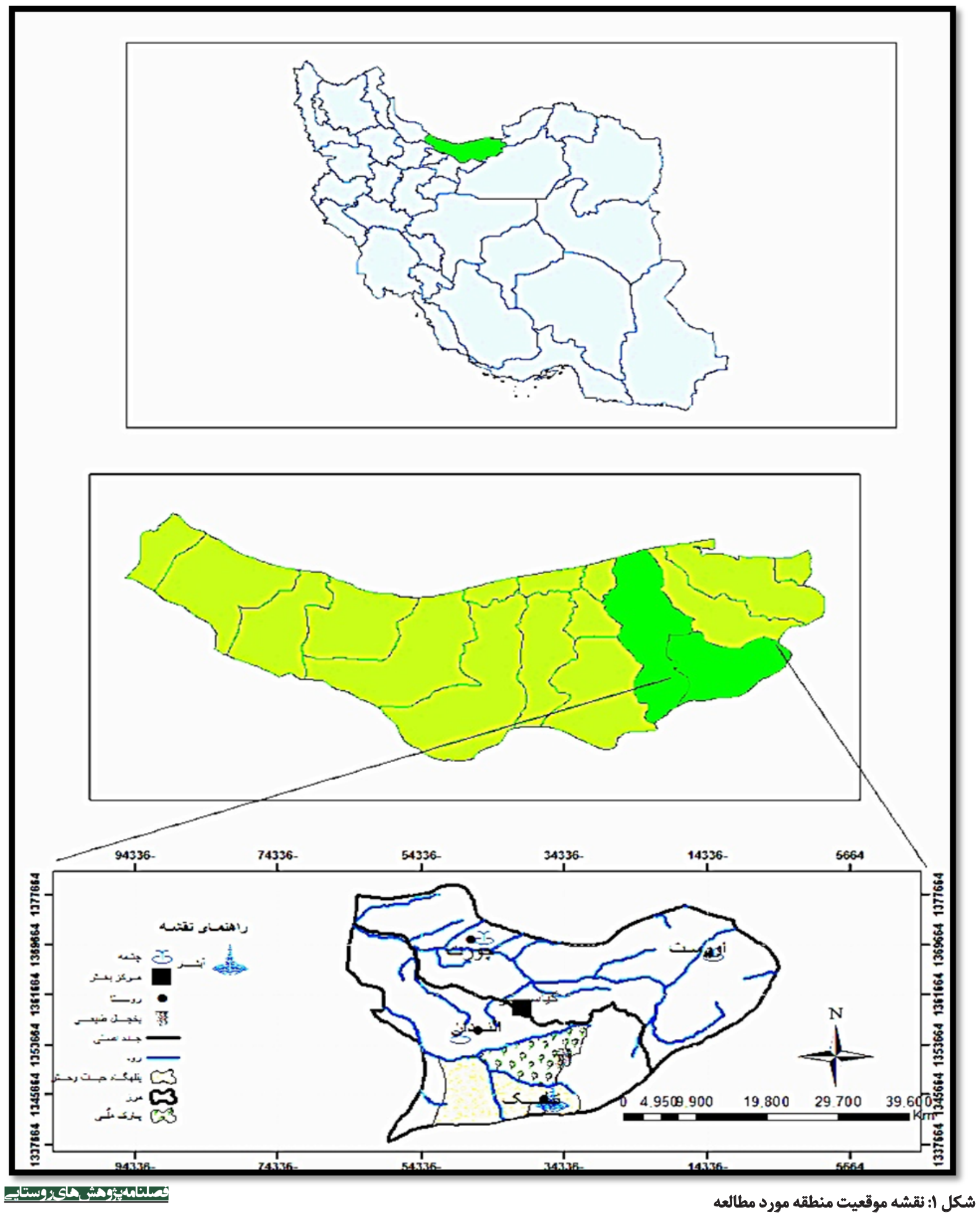

مكان براى توسعه كردشكَرى ارزشهاى علمى، فرهنكى، افزوده،

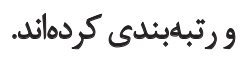
مديريتى و كاربردى دارد.

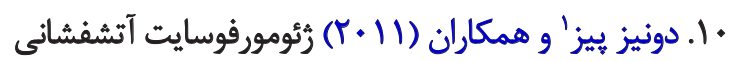

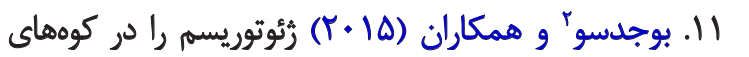
2. Bujdos رادر جزاير كانارى اسيانيا مطالعه كردئد. آنان نشان دادئد كه اين النئ 1. Doniz-Peaz 


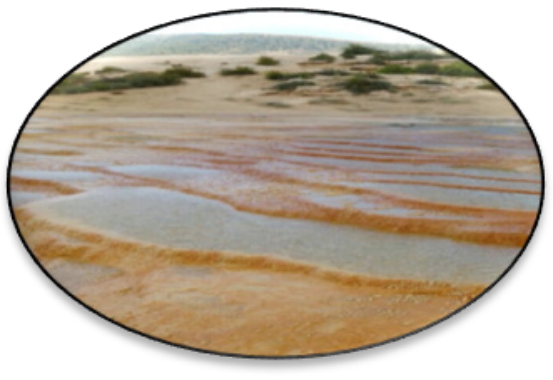

ب) جشمه بادابسورت.

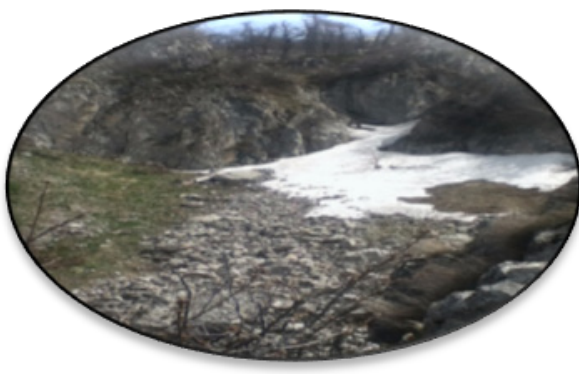

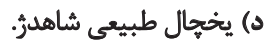

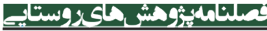

رُؤوسايتهاست. با توجه به توانمندى هاي بالقوه منطقه و قابليتهاي

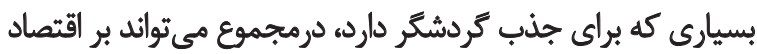

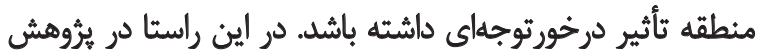

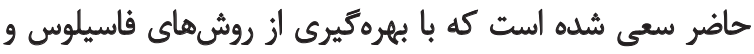

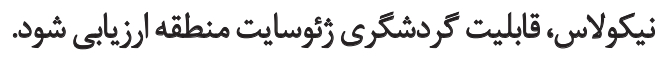
منطقه بروسى شُشده

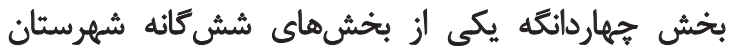

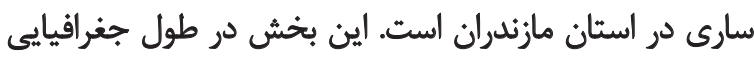

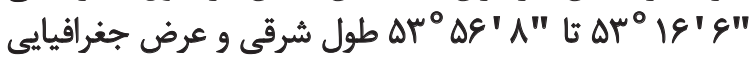

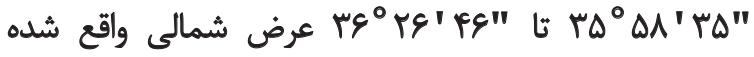
است (تصوير شماره 1). مركز اين بخش شهر كياسر است و در

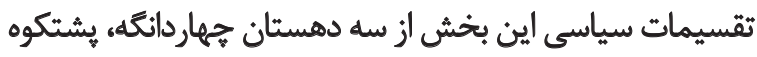
و گرماب تشكيل شده است. در اين بخش سه سه رئومورفوسايت

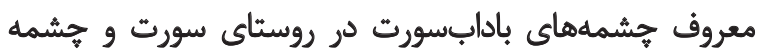

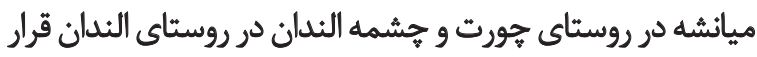

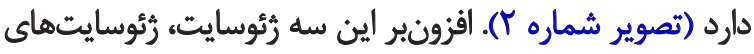

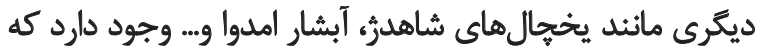
طبيعتى بسيار زيبايي به منطقه بخشيده است.

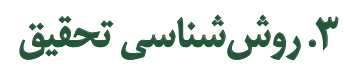

در اين يُروهش ابتدا بهوسيله مطالعهاي كتابخانهاي، با بررسي

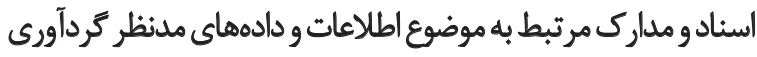

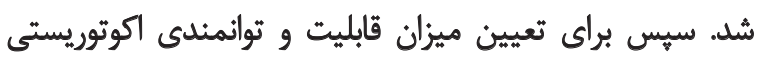
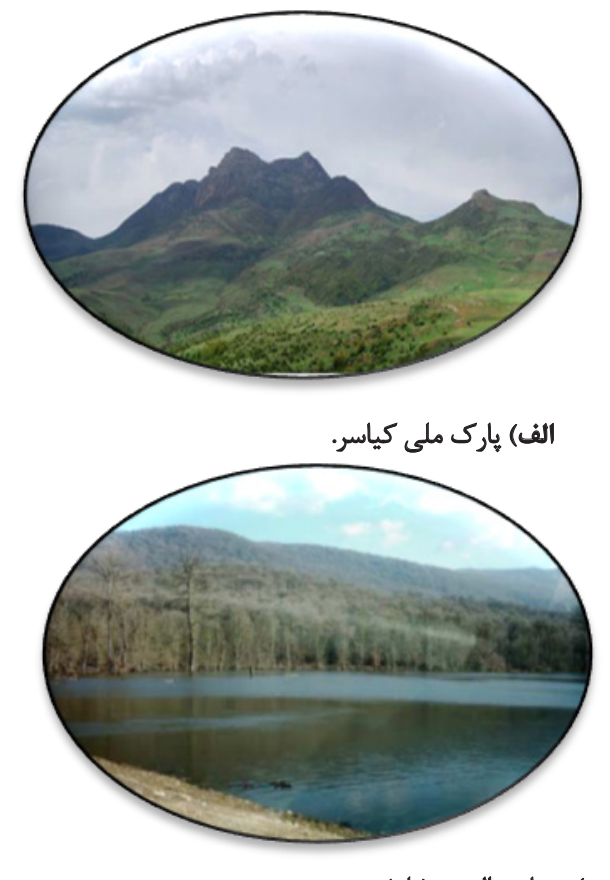

تصوير ب. تصاويرى از رئوسايتهاى منطقه بررسى شُده.

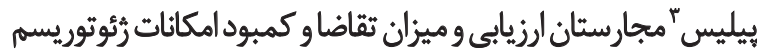

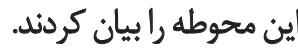

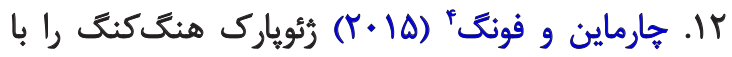

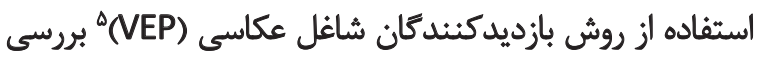

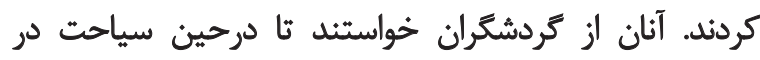

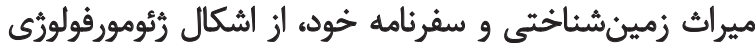

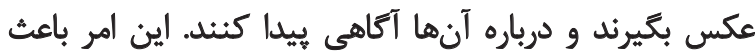

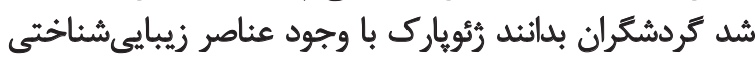

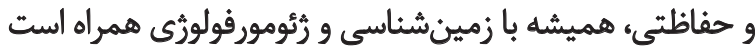

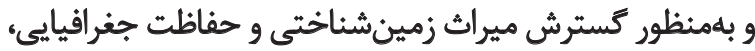

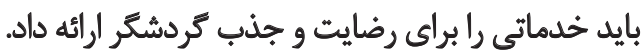

در ايران نيز تحقيقاتى از اين دست انجام شده است. براى نمونه،

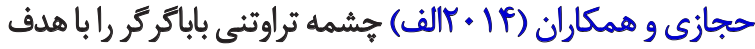

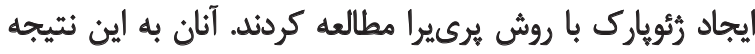

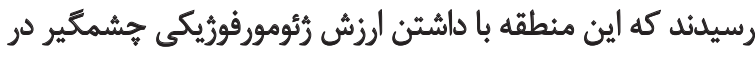

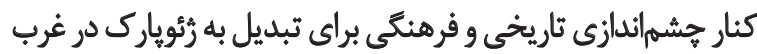

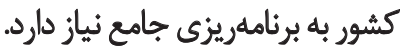

بخش جهاردانته شامل سه رئومورفوسايث معروف جشمه

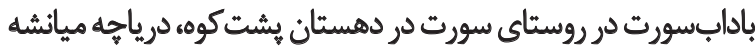

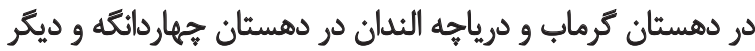

\section{Pilis}

4. Charmine and Fung

5. Visitor Empolyed Photograohy 


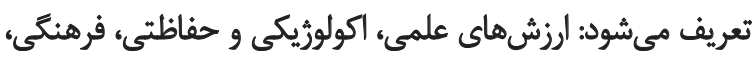

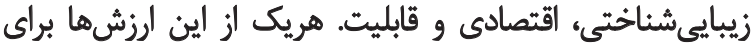

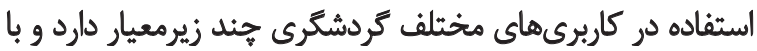

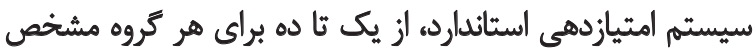
شده است (جدول شماره (1).

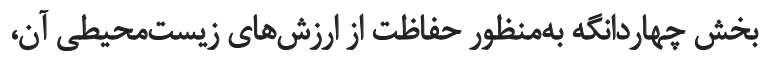
روشهاى فاسيلوس و نيكولاس به كاررفت.

روش فاسيلوس

در روش فاسيلوس، معيارها و ارزشها در شش گروه اصلى

جدول ا. معيارها و زيرشاخصهاى ارزيابى رئومورفوسايتها.

\begin{tabular}{|c|c|c|c|c|c|c|}
\hline 1. & $V / \Delta$ & $\Delta$ & $r / \Delta$ & 1 & تعريف شاخص & شاخص \\
\hline \multicolumn{7}{|c|}{ ارزش علمى } \\
\hline زمينشياى كل اشكوب & اشكوب محلى & كوياى تاريخ رخداد يا & كوياى تاريخ بيش از & كوياى تاريخ يك رخداد & \multirow{2}{*}{ تاريخ زمينشُناسى } & \multirow{2}{*}{$1 / 1$} \\
\hline \multicolumn{5}{|c|}{ 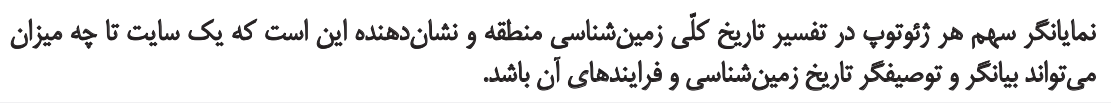 } & & \\
\hline خيلى بالا & بالا & متوسط & n & نيست & & \\
\hline \multicolumn{5}{|c|}{ 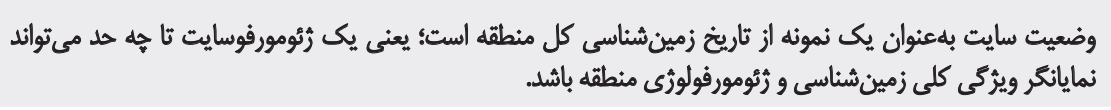 } & نمايانكربودن & $1 / r$ \\
\hline بيش از VA درصد & V V V Vرصد & مهر مرصد & هT درصد & ي ييش از ه درصد & & \\
\hline
\end{tabular}

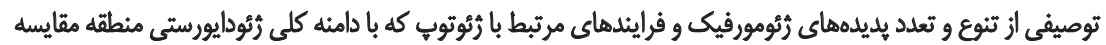

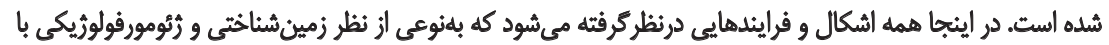

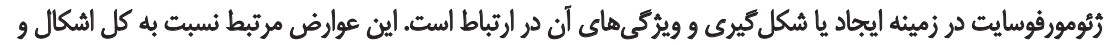

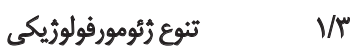

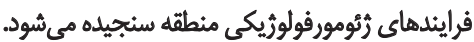
منحصربهفرد
$1-r$

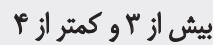

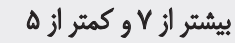
بيش از Vنموثه

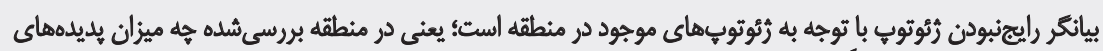

كميابى $1 / \%$

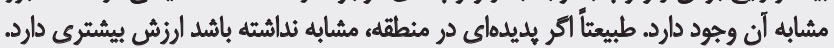

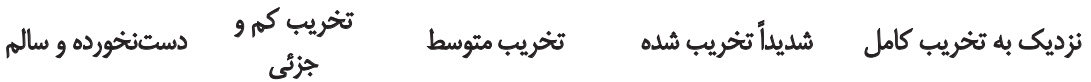

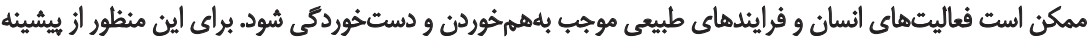

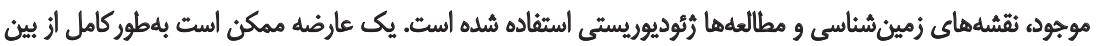

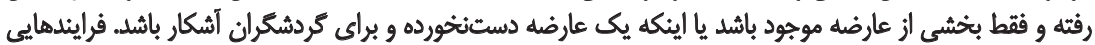

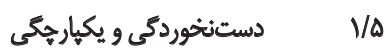

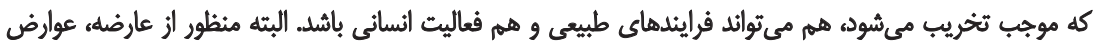

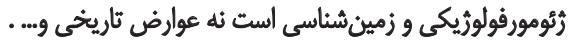

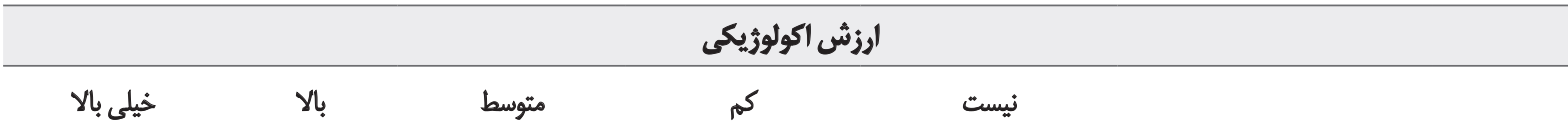

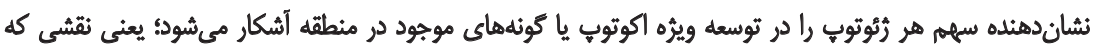

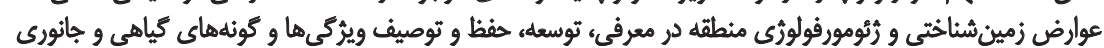
و درمجموع اكوسيستم منطقة دارد.
Ślls
بر بيشتر
در نقاط خاصى وجود
همدوديت ايجادشده
حفاظظيى وجود ندارد

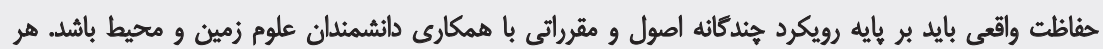

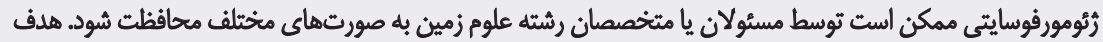
وضعيت محافظت $r / r$

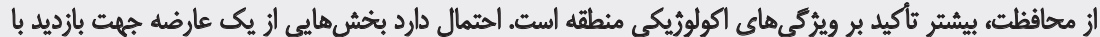

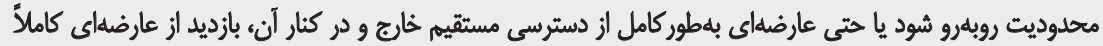




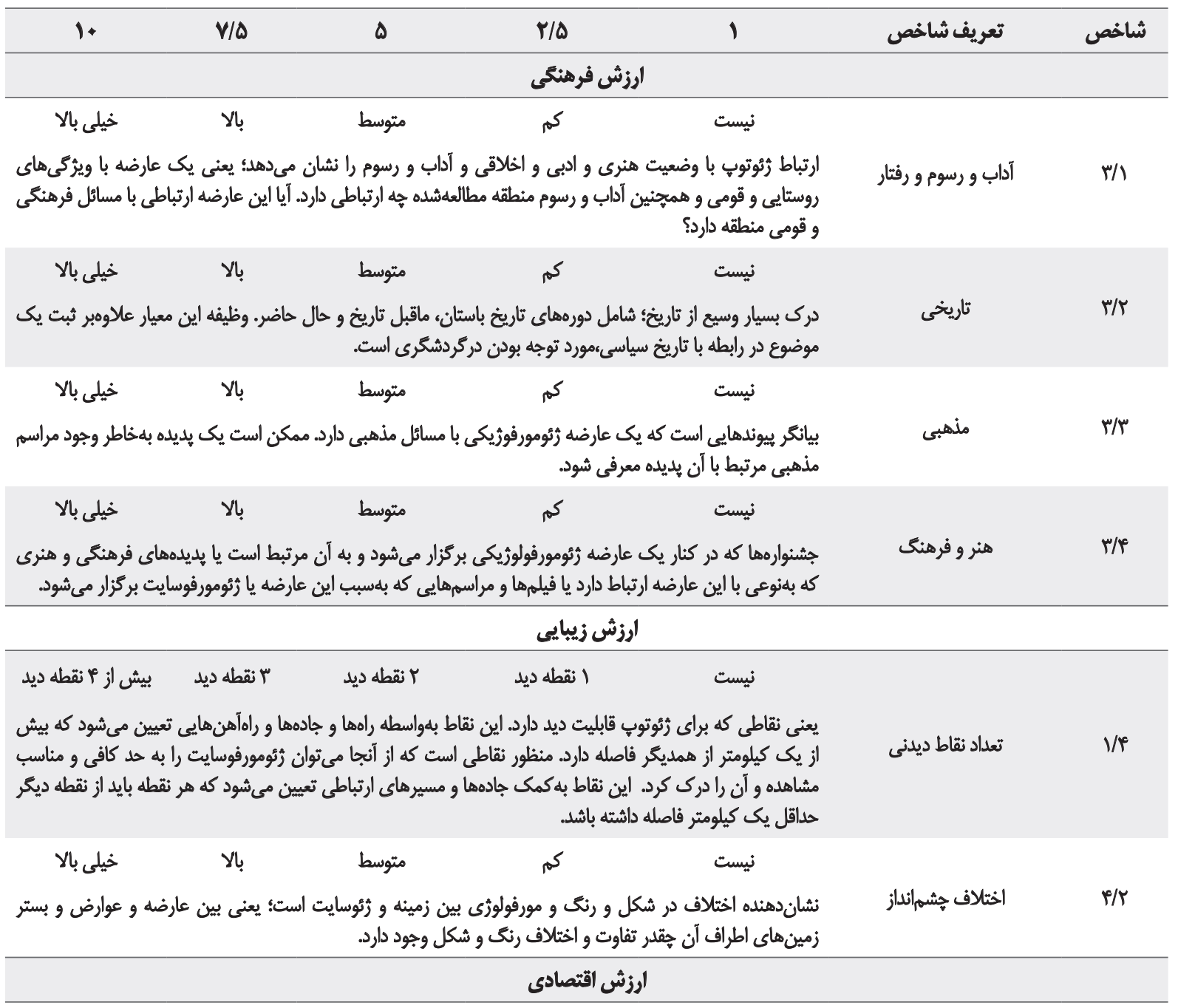

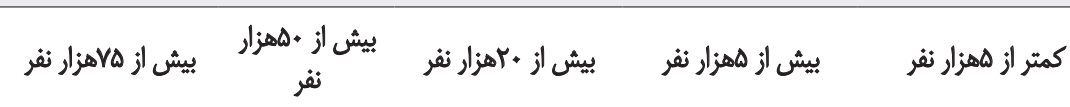
تعاد كرشكران كه هميشه با مجموع ظرفيت يثائسيل كرششكران منطقه يا كشور بايد مرثبط باشد.
بين/المللى
ناحيهاى
منطقةهاى
محلى
نيست

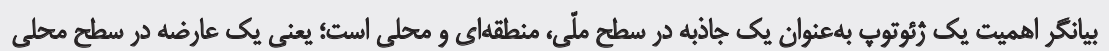
و يا محلى يا منطقهاى هقدر ارزش دارد.

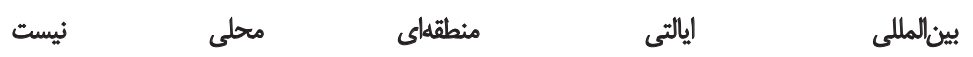

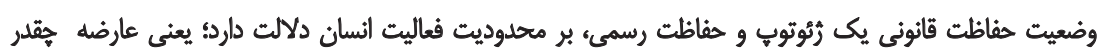

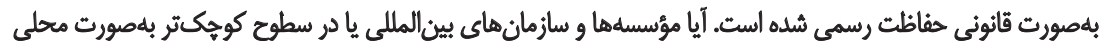

تعداد ثماشاكران

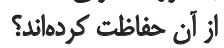

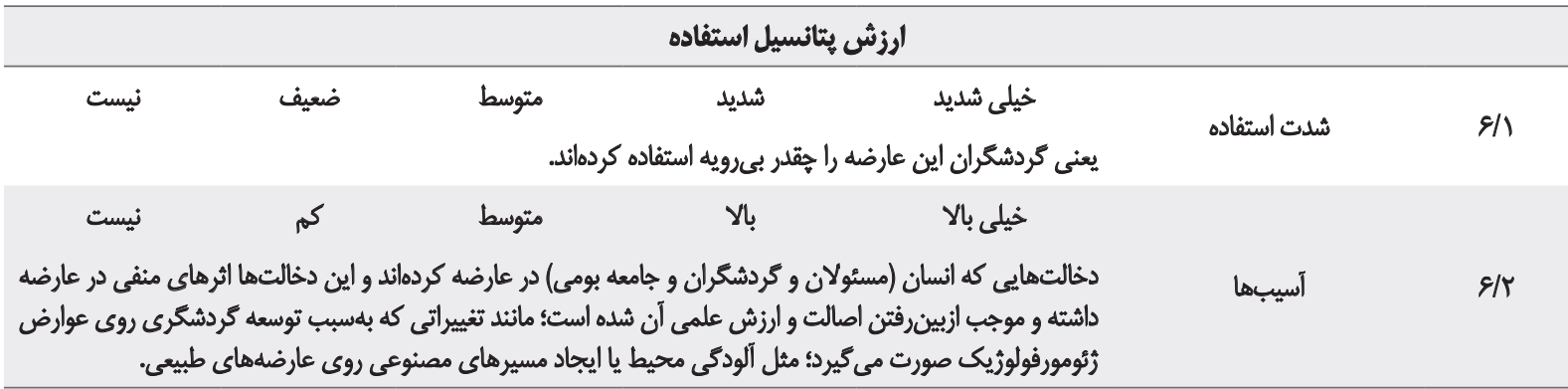




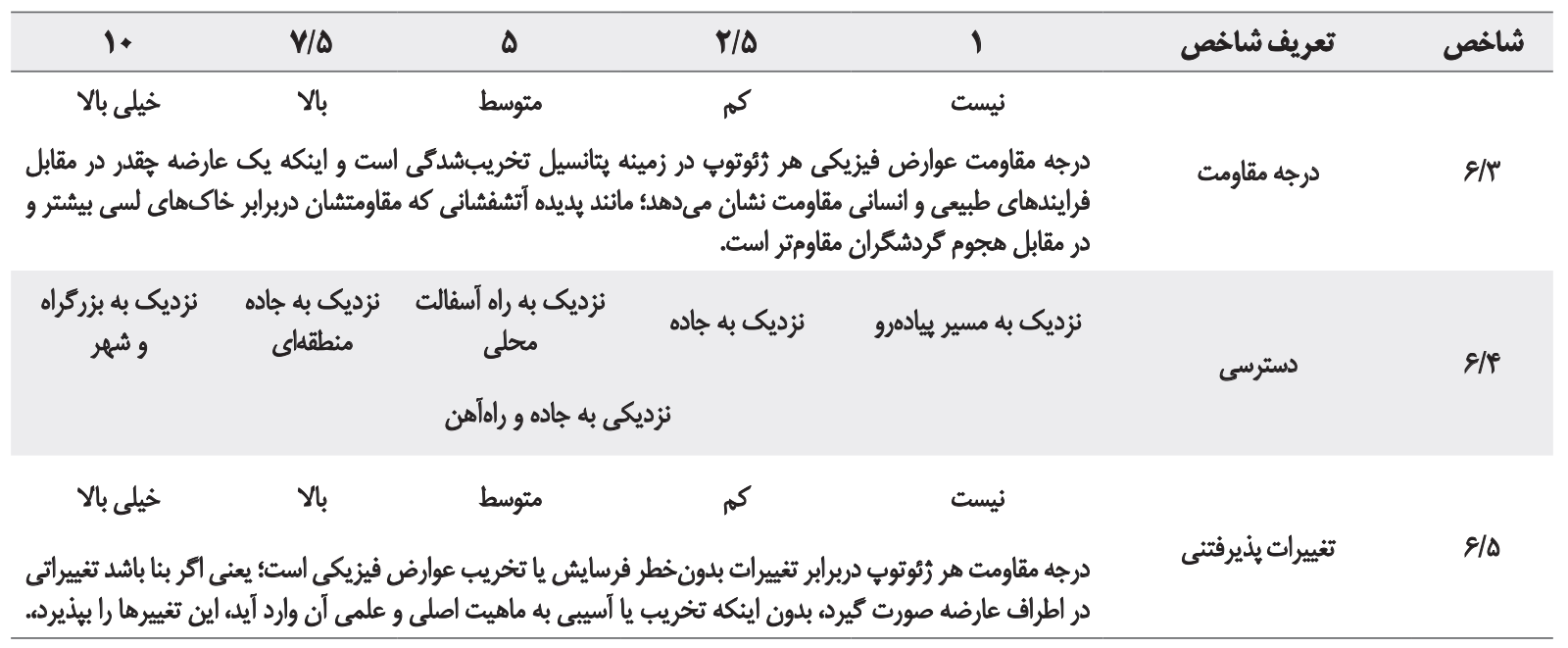

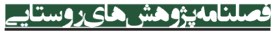

كارشئاسان مرتبط استفاده و با امتياز خاصي بيان و ارزش كلي

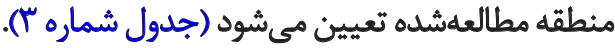

أ.

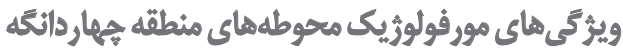

رُؤوتوريسم بهعنوان گزينهاى جديد نهتنها بر همه ويرّكى هاى

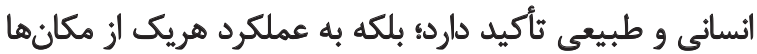

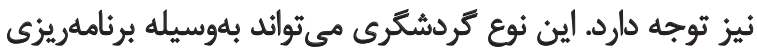

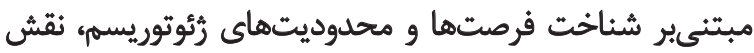

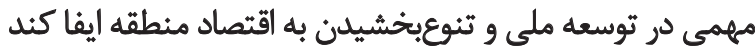

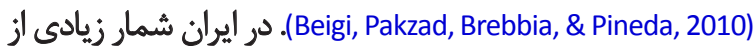

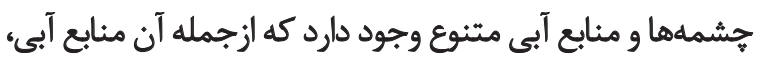

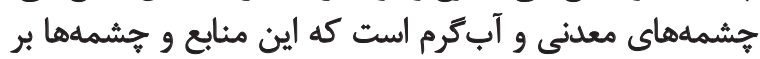
كر دشأرى ثأثير بسزائي دارد.

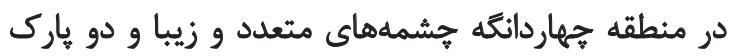

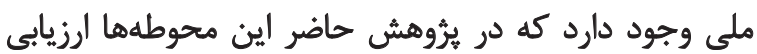

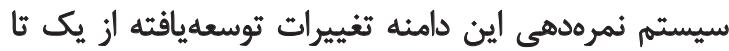

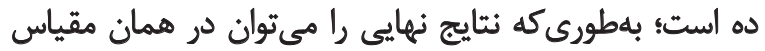

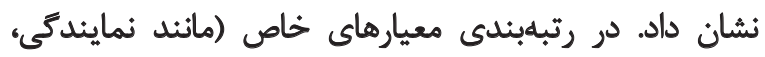

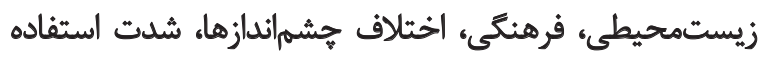

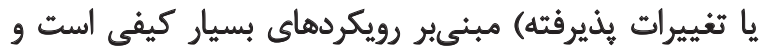

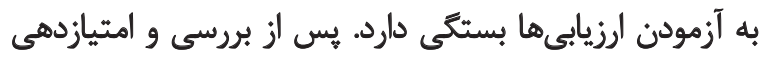

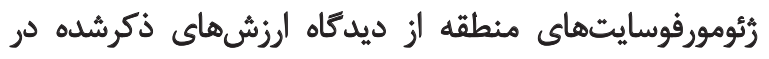

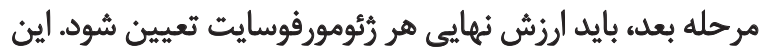

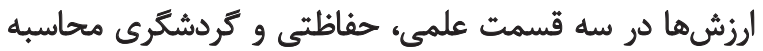

$$
\text { شود (جدول شماره r). }
$$

$$
\text { وروّن نيكولاس }
$$

در اين روش معيار هاى خاصى براى تعيين هريك از جنبههاى

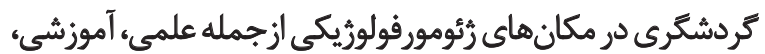

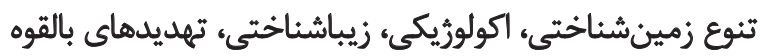

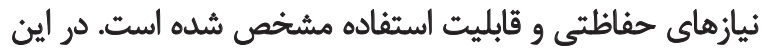

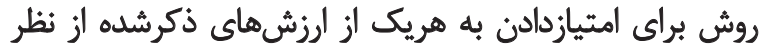

\section{جدول r. نحوه محاسبه ارزشهاي علمى، حفاظتى و كردشكُى در روش فاسيلوس.}

$\mathrm{V}_{\text {edu }}=0.4$ Scientific +0.2 Cultural+0.2 Aesthetic +0.2 Ecological

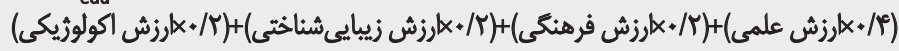

$V_{\text {tour }}=0.4$ Aesthetic +0.2 cultural+0.2 Potential of Use +0.2 Economic

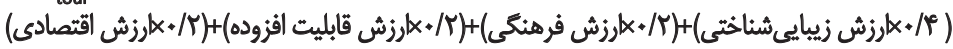

\section{$\mathrm{V}_{\text {prot }}=\left\{\right.$ Scientific $+\mathrm{F}_{\text {ecol }}+($ 11-Integrity) $\} / 3$}

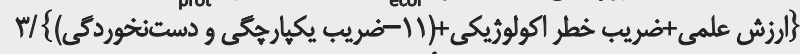

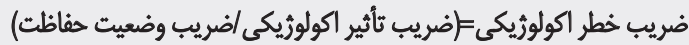


جدول r. معيارها و زيرشاخص هاى ارزيابع ثئومورفوسايتها.

\begin{tabular}{|c|c|c|c|}
\hline امثيازات & 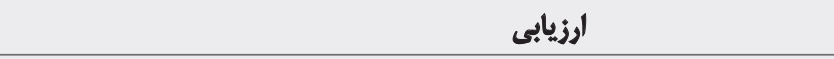 & & معيارها \\
\hline$-\infty$ & ارزش علمى و آموزشى & & 1 \\
\hline-1 & 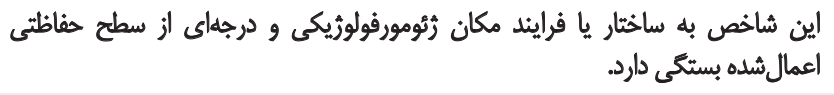 & وضعيت مكان & $1-1$ \\
\hline$\cdot-1$ & منطقلى شاخص، ملى و محلىرث). تعداد مكان هاى مشابه موجود در سطوح مختلف است (بينالمللى، & كمياني & $1-r$ \\
\hline+-1 & درجهاى كه يك مكان، نمونه بارز فرايند رُؤومورفولوزيكى خاص باشد. & ن مايندكى & $1-r$ \\
\hline-1 & 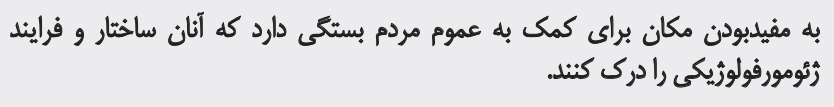 & نمونه & $1-f$ \\
\hline$\cdot-1$ & به تعداد اشكال رثئومورفولوزى و زمينشناختى جذاب و متنوع در هر مكان بستكى دارد. & تنتوع زمين شناختى & $r$ \\
\hline+-1 & 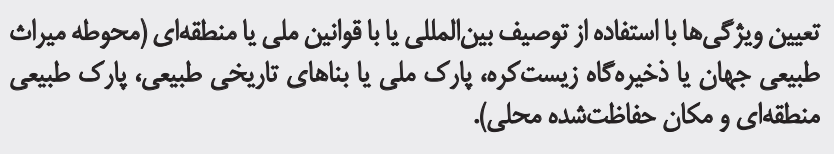 & ارزش اكولوزيكى و & r \\
\hline+-1 & 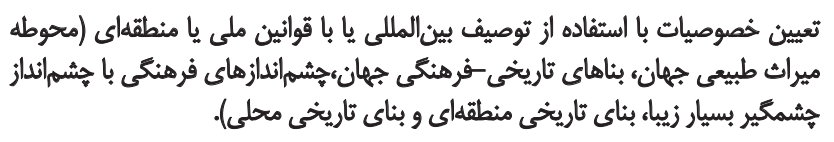 & ارزش فرهنكى & $r$ \\
\hline$\bullet-1+$ & تهديدهاى بالقوه و نيازهاى حفاظتى & & $\Delta$ \\
\hline$\cdot-\phi$ & 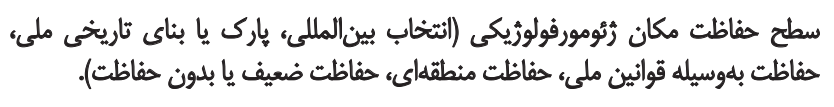 & حفاظت قانوثى & $1-\Delta$ \\
\hline$\cdot-\Delta$ & 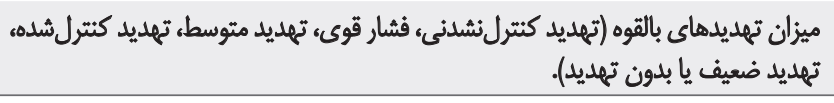 & آسيبذيذيرى & $r-\Delta$ \\
\hline$-r+$ & قابليت استفاده & & $q$ \\
\hline$\rightarrow \rightarrow$ & سا ناشناختهن). & قابليت تشخيص & $1-9$ \\
\hline$\cdot-\infty$ & درصد فضاى اشغال شده توسط مكان رئومورفولوزيك در ارتباط با سطح كلى منطقه. & توزيع جغرافيايي & $r-q$ \\
\hline$\cdot-\Delta$ & 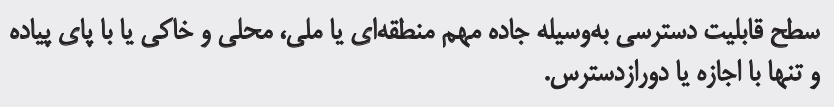 & قابليت دسترسيى & $r-q$ \\
\hline$\cdot-\Delta$ & 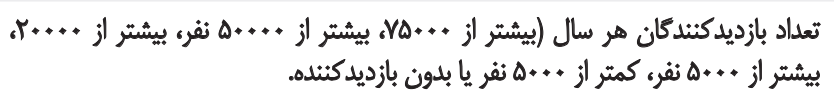 & قابليت استفاده & $p-8$ \\
\hline
\end{tabular}

استفاده از الكّوهاى رؤومورفوتوريستى در قابليتسنجى

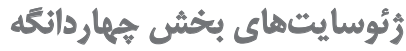

ارزيابى قابليت زئوسايتهاي منطقه براساس روش فاسيلوس

در اينجا محوطه هاي نامبر دمشده منطقه با روش فاسيلوس بررسي

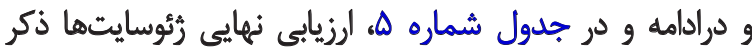

مىشود. اين منطقه بهدليل توانمندىهاى اكولوزيكى

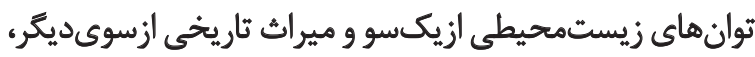

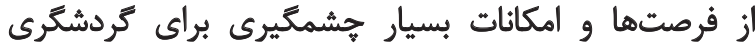
برخوردار است. در اين منطقه بيى توجهى و نبودمليريت صحيح

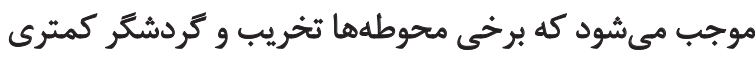
جذب و بهدنبال آن، اين صنعت با ركود اقتصادى روبه موبهرو شود. 
جدول F. ويرّكى هاي جشم|ائدازهاي خاص جهاردائكه.

\section{0.}

عارضه طييعى

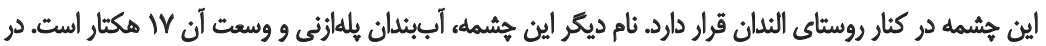

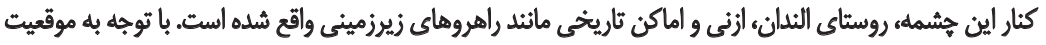

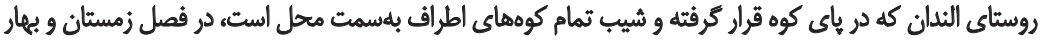

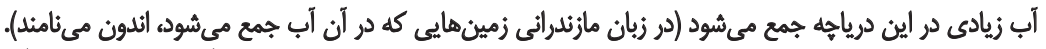

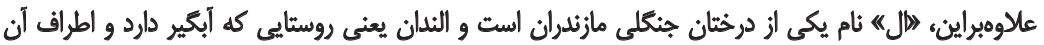

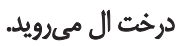

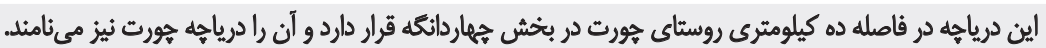

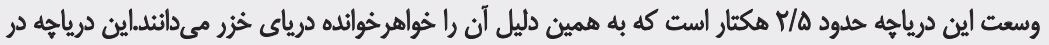

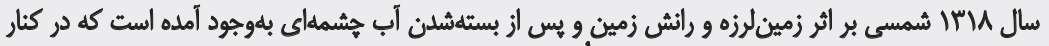

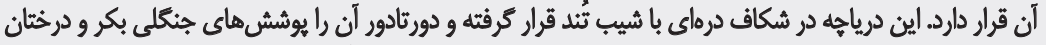

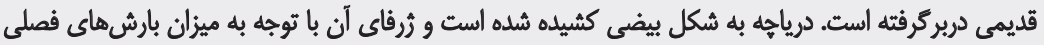

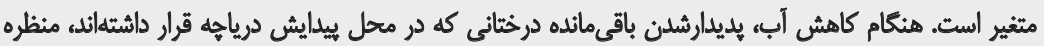

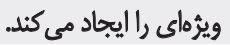

درياجه الثنان

درياهيه ميائشه

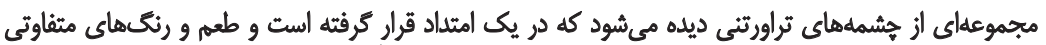

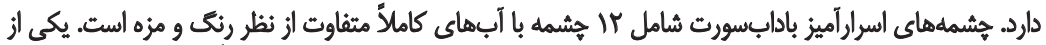

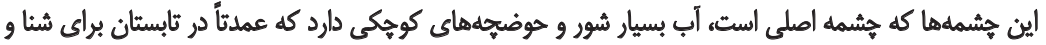

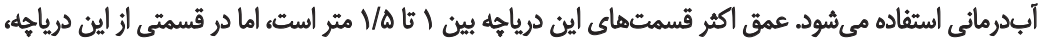

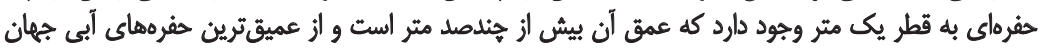

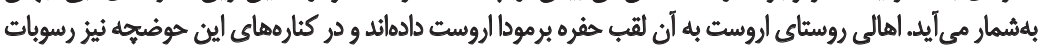

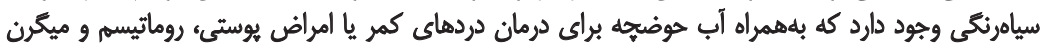

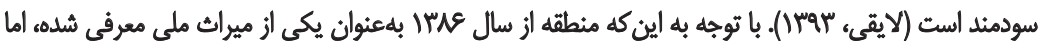

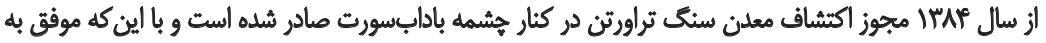

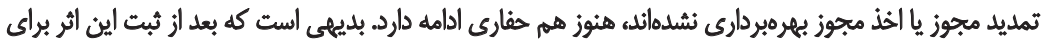

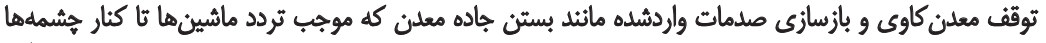

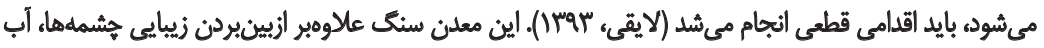

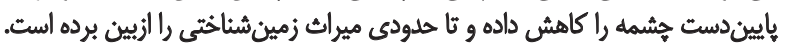

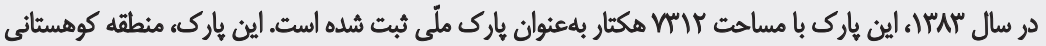

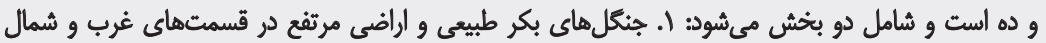

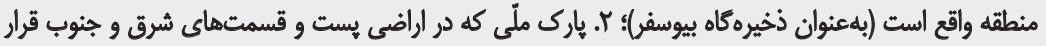

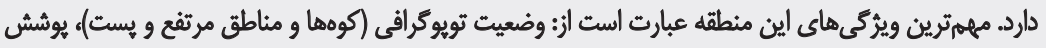

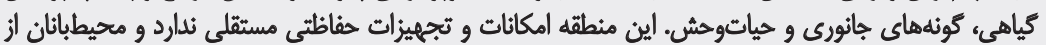
آن حفاظلت مى كنئد.

اين آبشار در شرق روستاي تيلى قرار دارد. نام ديكر اين آبشار، جيلينى جيلينك است و درحدود fال مثر ارتفاع دارد. جشمه سورت

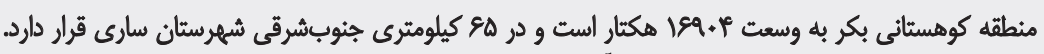

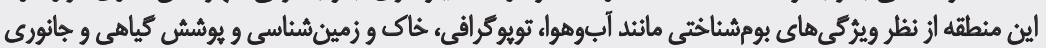

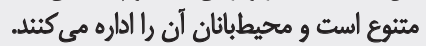

اين يخجالهاي طبيعى دائمى در ارتفاعات سههزار مترى قله شاهدر قرار دارد. اين قله بلهعنوان بام شهرستان معرفى شده است.

يناهكَاه حياتوحش دودانكَه

بارى ملي كياسر

آبشار اهدوا

مسئمس

اين محوطهما از شرايط مطلوبي برخوردار است. ويرّكي عمده اين

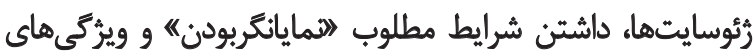

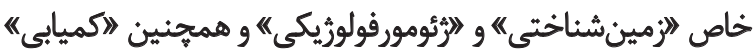

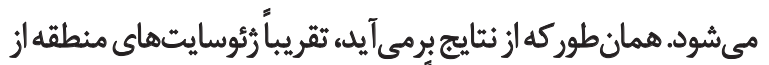

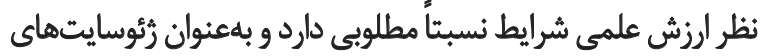

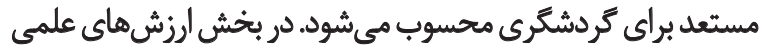


جدول هـ. ارزيابي نهايیى رُؤوموروسايتهاي بخش جهاردانكه با روش فاسيلوس.

\begin{tabular}{|c|c|c|c|c|c|c|c|}
\hline يخخجال طييعى & 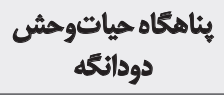 & آبشار امدوا & باركى ملى كياسر & بادابخسورته & مرياتشه & درياهِ الندان & \\
\hline 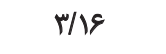 & $\Delta / V \Delta$ & $r / \& H$ & $\Delta / \Delta$ & Slorf & F/aYg & $\Delta / m g$ & ارزش علمى \\
\hline$r / \Delta A$ & r/qes & r/ofe & $\varphi / m p$ & P/OVf & F/TNE & p/vqs & ارزش كردشكرى \\
\hline$r / \Lambda$ & $V / \Delta$ & $\varphi /+\notin q$ & $\wedge$ & sles & s/1Fe & $s / \pi$ & ارزش حفاظتى \\
\hline NAf & $|V / r| q$ & II/TET & IV/Af & IV/VAA & $1 \Delta / \pi \checkmark A$ & $1 \& / \Delta \cdot r$ & هجموع \\
\hline
\end{tabular}

然

جدول \&. ارزيايى نهايي رُؤومورفوسايتهاي بخش جهاردانكه با روش نيكولاس.

\begin{tabular}{|c|c|c|c|c|c|c|c|}
\hline طيخجال & وخش دو دائكه & آبشار امدوا & كيارى ملّى & شهورت باداب & مرياته & الندياجه & معيار \\
\hline 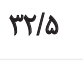 & $\varphi+$ & r. & f. & $r V / \Delta$ & $r v / \Delta$ & $m V / \Delta$ & ارزش علمى و آموزشى \\
\hline r & $V / \Delta$ & $\Delta$ & $\Delta$ & 1. & $V / \Delta$ & $\Delta$ & تنوع زمينشناختى \\
\hline$\Delta$ & 1. & $\Delta$ & 1. & 1. & 1. & 1. & ارزش اكولوزيكى و زيبائشئاختى \\
\hline 1 & $T / \Delta$ & $T / \Delta$ & $r / \Delta$ & 1. & $V / \Delta$ & $V / \Delta$ & الوزش فرهنكى \\
\hline 1 & r & 1 & $\&$ & $\Delta$ & r & r & تهديدهاي بالقوه و ثيازهاي حفاظثي \\
\hline$\Delta$ & ir & $\Delta$ & if & ir & ir & if & قابليت استفاده \\
\hline re/D & $\Delta V / \Delta$ & HND & $9 V / \Delta$ & $N \& / \Delta$ & 99 & VA & مجموع \\
\hline
\end{tabular}

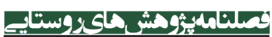

ارزش علمى جشمكير و ارزش كردشكرى كمى دارد.

در بخش ارزشهاى حفاظتى بارك ملى كياسر و وَّاهناه

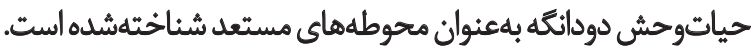

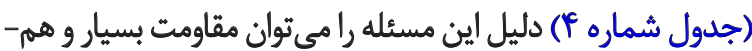
جنين محافظت ادارى محوطهها دانست.

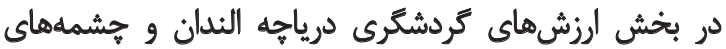

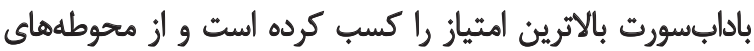

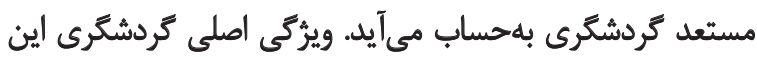

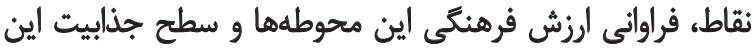

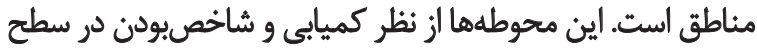
ملى و منطقهاي شئاخته شده است.

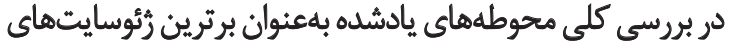

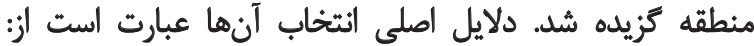

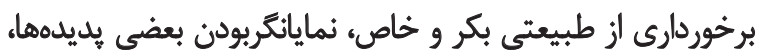

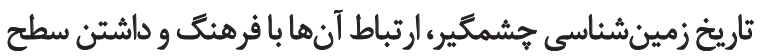

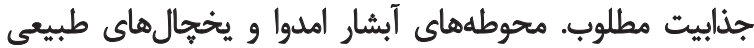

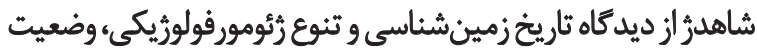

اين آثار زمينشناختى در ايران است. اين موضوع نشان مى دهد كه

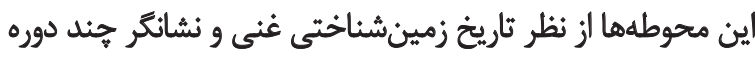
زمينشناختي در منطقه است.

در ارزيابى جشمههاى بادابسورت، الندان و جورت علاومبر

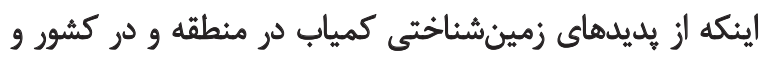

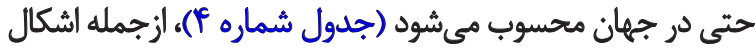

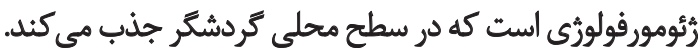

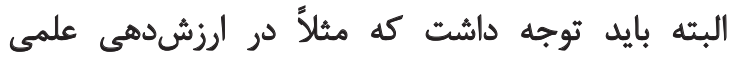

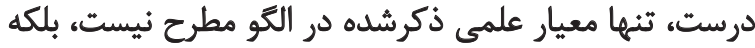

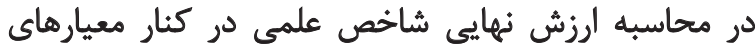

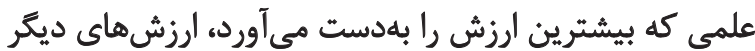

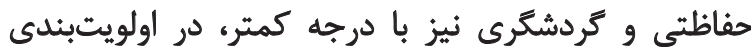

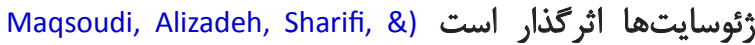

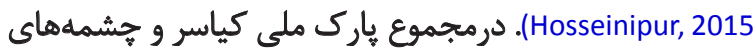

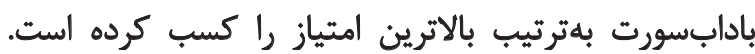

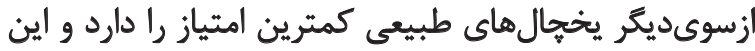

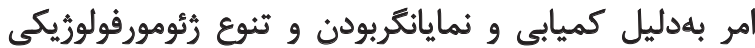

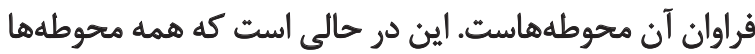




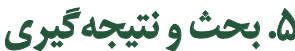

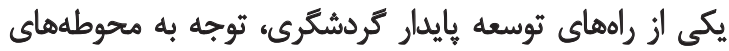

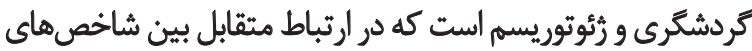

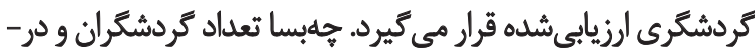

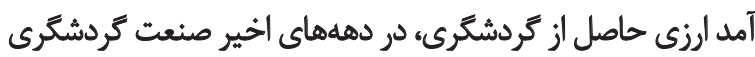

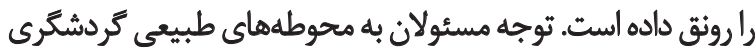

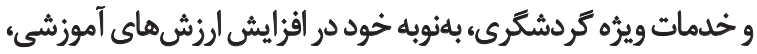

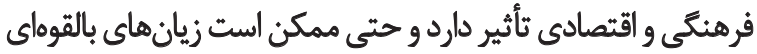

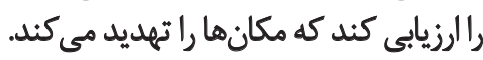

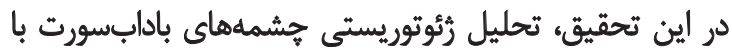

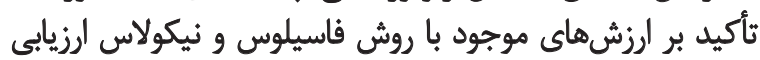

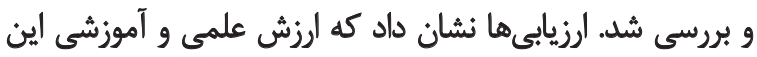

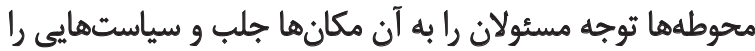

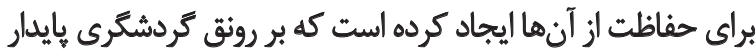

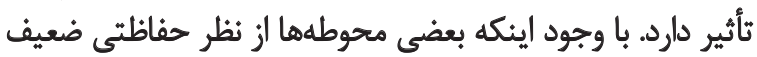

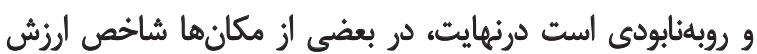

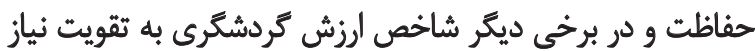

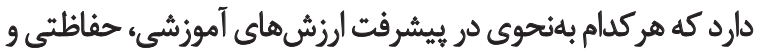
حتى كردشكرى مؤثر است.

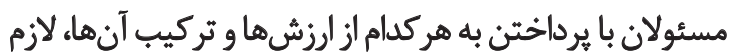

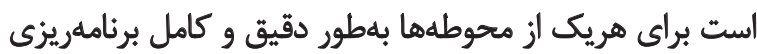

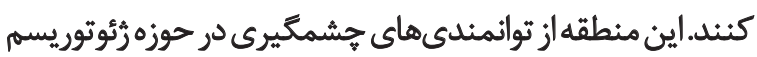

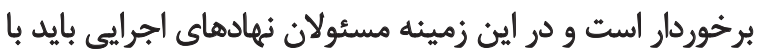

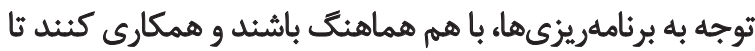

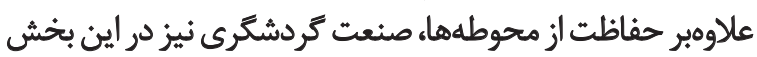
با موفقيت روزافزونى همراه شودا معان

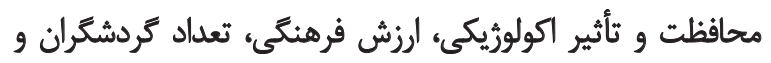

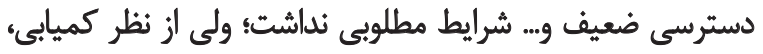
شاخصبودن و... شرايط ايدهآلى داشت.

درواقع رئوسايتها همان مكانهاى رئومورفيك است كه ميراث

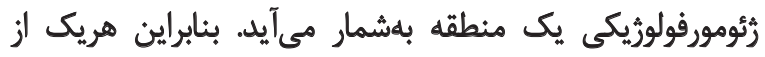

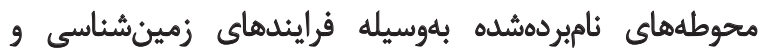

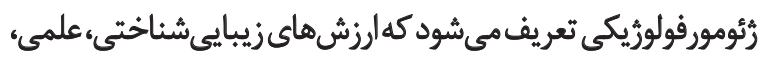

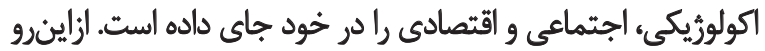

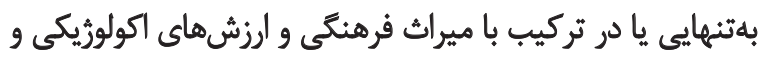

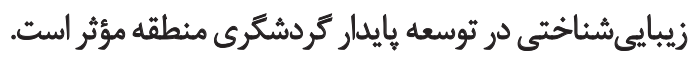
براي تعيين ميزان اهميت و ارزش كلى هريك از رئوسايتها،

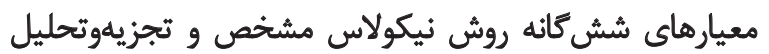

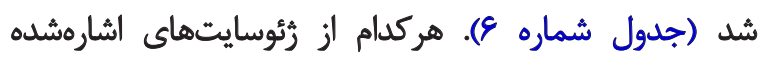

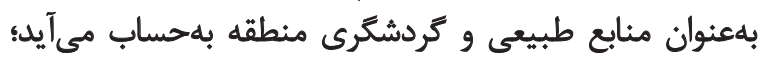

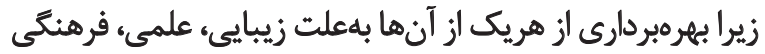

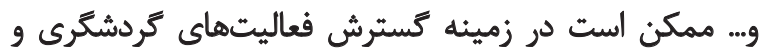
شاخص هاى اقتصادى مؤثر باشد.

براساس جدول شماره وبيشترين ارزش متعلق به جشمهاهياي

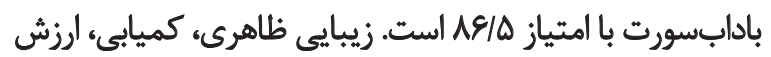

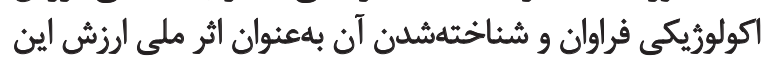

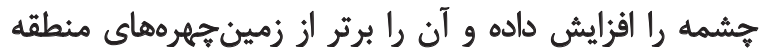

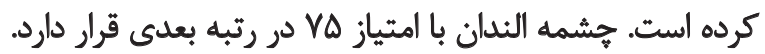

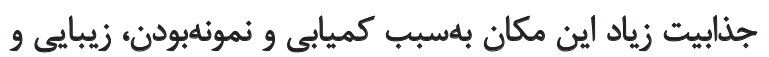

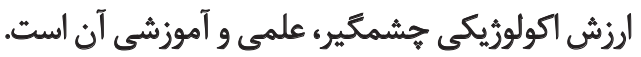
از ميان رئوسايتهاى محوطه ذكرشده، آبشار امدوا و ورائ

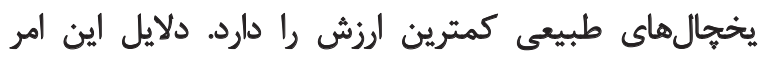

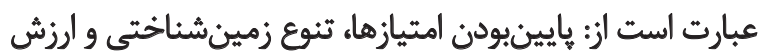

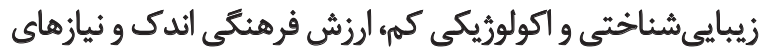

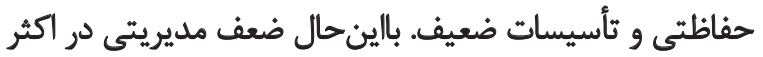

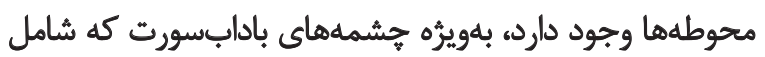
بالاترين ارزش است. يكى از دلائ دايل ديكر امتياز كم در همده

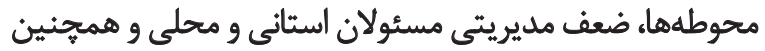

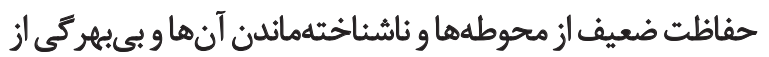

$$
\text { حمايتهاي قانوئى است. }
$$

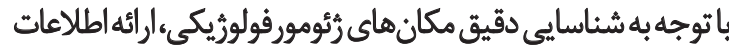

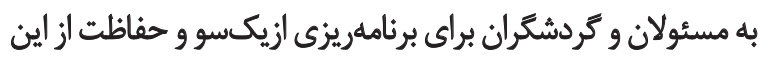

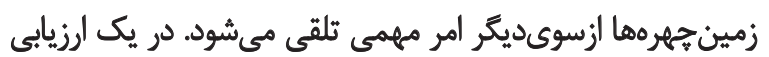

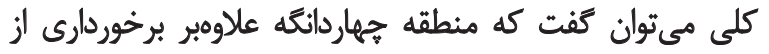

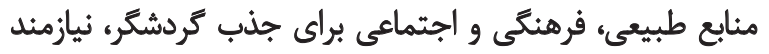

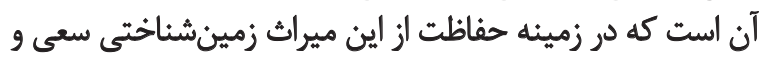
برنامهيزى هاى جامعى طراحى شود. 


\section{References}

Amri Kazemi, A. (2011). [Geopark and geotourism atlas abilities Iran (Persian)]. Tehran: Geological Exploration Organization of Iran Press.

Bagheri, S. M., Alandani, M., \& Bagheri, S. (2013). [Tourism caring healthy development within the mineral water boiling SuortBadab (Persian)]. Paper presented at National Conference on Tourism, National Properties and Future Vision, Esfahan, Iran, 10 February 2013.

Beigi, H., Pakzad, P., Brebbia, C. A., \& Pineda, F. D. (2010). Investigating geotourism capabilities of the Gavkhoni wetland according to the SWOT model. Paper presented at the $4^{\text {th }}$ International Conference on Sustainable Tourism, Dar es salaam, Tanzania, 28-29 July 2016.

Bojdoso, Z., David, L., Weber, Z., \& Tenk, A. (2015). Heritage as an alternative driver for sustainable development and economic recovery in South East Europe; Utilization of geoheritage in tourism development. Social and Behavioral Sciences, 188, 316-24.

Comanescu, L., \& Dobre, R. (2011). Evaluation of geomorphosites in Vistea valley (Fagaras Mountains-Carpathians, Romania). International Journal of Physical Sciences, 6(5), 1161168.

Dóniz-Páez, J., Becerra-Ramírez, R., González-Cárdenas, E., Guillén-Martín, C., \& Escobar-Lahoz, E. (2011). Geomorphosites and geotourism in volcanic landscapes: the example of La Corona del Lajial cinder cone (El Hierro, Canary Islands, Spain). Geo Journal of Tourism and Geosites, 2(8), 185-97.

Farmani Mansour, S., Hejazi, S. A., \& Beheshti, T. (2014). [Karsti sources of gravitational geomorpho-tourismi for sustainable tourism development: Case Nahavand plain (Persian)]. Paper presented at the $2^{\text {nd }}$ International Conference on Sustainable Development, Strategies and Challenges with a Focus on Agriculture, Natural Resources, Environment and Tourism. Tabriz, Iran, 24-26 February 2015.

Fung, C. K., \& Jim, C. Y. (2015). Unraveling Hong Kong Geopark experience with visitor-employed photography method. Applied Geography, 62(3), 301-13.

Fassoulas, C., Mouriki, D., Dimitriou-Nikolakis, P., \& Iliopoulos, G. (2012). Quantitative assessment of geotopes as an effective tool for geoheritage management. Geoheritage, 4(3), 177-93.

Fennell, D, A. (1999). Ecotourism: an introduction. Philadelphia: Routledge Publication.

Hijazi, S. A. Farmani, M., \& Setareaflaki, Z. (2014). [Check springs travertine Baba Gorgor in Qorveh to create geopark (Persian)]. Paper presented at the $1^{\text {th }}$ National Conference on Geography, Tourism, Natural Resources and Sustainable Development, Tehran, Iran, 19 February 2015.

Hijazi, S. A., Farmani Mansour, S., \& Ildermi, A. (2014). [Analysis of forest ecotourism Kian Nahavand, using the method of Nicholas (Persian)]. Paper presented at the $1^{\text {th }}$ National Conference on Sustainable Development of Renewable Natural Resources, Hamadan, Iran, 24 October 2014.

Joyce, E. B. (2010). Australia's geoheritage: history of study, a new inventory of geosites and applications to geotourism and geoparks. Geoheritage, 2(1-2), 39-56.
Layeghi, S., (2014). [Iran tourism attractions: case study of Badab Sort (Persian)]. Paper presented at the $1^{\text {th }}$ National Conference on Sustainable Development, Tehran, Iran, 27 February 2014.

Maghsoudi, M., Alizadeh, M., Sharifi, A., \& Hosseinipur, S. (2015). [Solomon's throne geomorphosites quantitative assessment methods, with emphasis on the development of geotourism Fasilous (Persian)]. Quantitative Geomorphological Researches, 3(3), 22-37.

Molaei Hashtjin, N., \& Kalavan Rajabi, P. (2011). [The city of Taft, knowing the tourism environment for the development of ecotourism (Persian)]. Natural Geography Quarterly, 4(17), 1-12.

Mirkatouli, J., Zangiabadi, Z., Aflaki, Z., \& Mousazadeh, H. (2016). [Assessment of geological heritage in Badab Surt Geopark Springs with Pereira and Reynard Methods (Erusr rural- Sari Region) (Persian)]. Journal of Regional Planning, 6(21), 205-220.

Nickolas, C., Zouros, N. (2007). Geomorfosite assessment and management in procted areas of Greece. Case study of the Lesvos is land costal geomorphosites. Geographica Helvetica, 62(3), 169-80.

Necula, R., \& Necula, D. (2011). Perspectives in rural tourism - the geopark in Buzau county, Engineering in Agriculture and Rural Development, 11(3), 169-71.

Ranjbaran, M. (2011). [Geomorphology and petrography of Badabe Surt travertine springs north of Damghan, Iran (Persian)]. New Findings in Applied Geology, 5(9), 47-56.

Reynard, E., Fontana, G., Kozlik, L., \& Scapozza, C. (2007). A method for assessing "scientific" and "additional values" of geomorphosites. Geographica Helvetica, 62(3), 148-58.

Veysi, A., Chitsaz, M., Karami, A., \& Kianpour, P. (2014). [Identification and feasibility geomorphotourism city Abdanan using quantitative evaluation methods and Fasilous and Rennard (Persian)]. Paper presented at the Iranian Conference Geographical Sciences, Tehran, Iran, 20 May 2014.

Veysi, A., \& Chitsaz, M. (2014). [Assessment of geomorphosites of West Guilan using Fasilos method (Persian)]. Paper presented at the $1^{\text {th }}$ National Conference on Sustainable Development of Renewable Natural Resources, Hamadan, Iran, 24 October 2014

Veysi, A., Karami, A., Chitsaz, M., \& Kianpour, P. (2014). [Assessment of the potentials of geomorphosites of Vizhnan region using quantitative methods (Persian)]. Paper presented at the $1^{\text {th }}$ National Conference on Sustainable Development of Renewable Natural Resources, Hamedan, Iran, 24 October 2014.

Wójtowicz, B., Strachowka, R., \& Strzyz, M. (2011). The perspectives of the development of tourism in the areas of geoparks in Poland. Social and Behavioral Sciences, 19, 150-157. doi: 10.1016/j. sbspro.2011.05.118

Xun, Z., \& Milly, W. (2002). National geoparks initiated in China: putting geoscience in the service of society. Episodes, 25(1), 33-37.

Yamani, M., Negahban, S., Rahimi Abad, S., \& Alizadeh, M. (2012). [Geomorphotourism and geomorphosites evaluation and comparison methods in tourism development: Case Study, Hormozgan province) (Persian)]. Journal of Tourism Planning and Development, 1(1), 83-104. 
